\title{
Identifying Factors Associated With Hypertension Using Structural Equation Modeling: Evidence from a Large Kurdish Cohort Study in Iran
}

\section{Farid Najafi}

Kermanshah University of Medical Sciences

Mehdi Moradinazar

Kermanshah University of Medical Sciences

Shahab Rezayan

Kermanshah University of Medical Sciences

Reza Azarpazhooh

Western University

Parastoo jamshidi ( $\nabla$ p.jamshidi122@gmail.com )

Kermanshah University of Medical Sciences

\section{Research Article}

Keywords: Hypertension, Structural Equations Modeling, latent variable

Posted Date: January 31st, 2022

DOI: https://doi.org/10.21203/rs.3.rs-1174192/v1

License: (9) This work is licensed under a Creative Commons Attribution 4.0 International License. Read Full License 


\section{Abstract}

\section{Background}

Identifying the risk factors leading to hypertension can help explain why some populations are at a greater risk for developing hypertension than others. The present study seeks to identify the causal paths among the risk factors of hypertension in 35- to 65-year-old participants in western Iran.

\section{Methods}

The secondary analysis was conducted using the data obtained in the recruitment stage of Ravansar Non-Communicable Disease (RaNCD) cohort. Each of the latent variables were confirmed by confirmatory factor analysis. Using Structural Equation Modeling (SEM), we assessed the direct and indirect effects of the risk factors associated with hypertension.

\section{Results}

Socioeconomic status (SES), physical activity, lipid profile, obesity, Diabetes and family history of hypertension had a diverse impact on the blood pressure, directly and (or) indirectly. When investigating the latent and observers risk factors and the interrelations between different risk factors, The standardized total effect (the sum of direct and indirect effects, $\beta_{t}$ ) of SES, physical activity, lipid profile, obesity, on the blood pressure was( -0.09 vs -0.14$),(-0.04$ vs -0.04$),(0.13$ vs 0.13$),(0.24$ vs 0.15$)$ in men and women respectively. Diabetes had a direct relationship with the blood pressure in women $(0.03)$.

\section{Conclusion}

With regard to control of high blood pressure, public health interventions must target obesity,SES, lifestyle and nutritional factors such as hyperlipidemia and hyperglycemia in Iranian population

\section{Introduction}

Hypertension is one of the most important risk factors for chronic heart diseases(1,2). The incidence of hypertension has increased over the last few decades; the number of adults with hypertension has increased from 595 million in 1975 to 1.13 billion in 2015 (1). the prevalence of hypertension is predicted to increase $29.2 \%$ by 2025 and This increase has largely occurred in low-to middle-income countries $(3,4)$. The relationship between high blood pressure and cardiovascular disease and its mortality has been addressed in a number of observational studies(5). Hypertension shows an independent relationship with the incidence of several cardiovascular events such as stroke, myocardial infarction, heart failure and peripheral arterial disease as well as kidney disease. This relationship is shown for all ages and in all ethnic groups $(6,7)$.

Hypertension have a wide range of risk factors including, genetic, behavioral, environmental origin or other medical conditions $(8,9)$. Identifying the risk factors associated with hypertension can help explain 
why some populations are at a greater risk for developing hypertension than others. Studies have shown that, after adjustments for age and gender in different populations, hypertension are associated with body mass index (BMI), the level of physical activity and genetic factors, overweight/obesity, smoking, high cholesterol, diabetes mellitus, and other lifestyle factors (10-12). Nonetheless, these risk factors have not yet been simultaneously examined in a series that assesses the causal relationships leading to the outcome. By assessing the effect of the latent variables, Structural Equation Modeling (SEM) is the most useful method for the concurrent testing of complex relationships between variables(13). SEM is a powerful multivariate analysis method of multivariate regression that allows for the simultaneous verification of a series of regression equations(14) and a concurrent assessment of the relationships between different variables(15) .

SEM reduces measurement errors by involving several overt variables for each latent variable. Unlike traditional regression models that treat each covariate in the model as an independent direct effect, SEM allows to test the model with several dependent variables and assess the concurrent direct and indirect effects of several independent variables on the dependent variable. Available research allows us to hypothesize a causal model that depicts the relationships between factors related to the development of hypertension in terms of direct and indirect (i.e, mediator) effects. The present research was conducted to use SEM to identify the (direct and indirect) causal paths between the risk factors associated with hypertension in in the Ravansar Non-Communicable Disease (RaNCD) cohort.

\section{Materials And Methods}

\section{Study design and participants}

We used data from (RaNCD) cohort study. Ravansar is a city in Kermanshah Province which is located in western Iran close to the border with Iraq, with a population mainly comprised of Kurdish ethnicity. The RaNCD cohort is part of the large PERSIAN (Prospective Epidemiological ReSearch in IrAN) study. The study began in November 2014 and continues to date. Data from the recruitment phase of the study has been collected and includes general data, a nutrition questionnaire, and biological samples. More information is available in the cohort protocol and preliminary results $(16,17)$.

\section{Inclusion and exclusion criteria}

The data used in this study pertained to more than 10000 participants aged 35 to 65 who had voluntarily entered the study. For the purpose of this study we excluded those with a clinical history of stroke (50 subjects), myocardial infarction (65 subjects), renal failure (53 subjects).

\section{Definitions and measurements}

Anthropometric indices including body weight, height, waist to hip ratio and body mass index, waist circumference were measured according to standard methods. Body weight was measured using BioImpedance Analyzer BIA (Inbody770, Inbody Co, Seoul, Korea) with a precision of $0.5 \mathrm{~kg}$. Height was 
measured by BSM370 (Biospace Co, Seoul, Korea) with the precision of $0.1 \mathrm{~cm}$. Body mass index (BMI was measured by dividing weight $(\mathrm{kg})$ by the square of height $(\mathrm{m})$. The Waist to Hip Ratio (WHR) was calculated by dividing the waist circumference by the hip circumference. WC was measured with a flexible measuring tape at a level midway between the lower rib margin and the iliac crest to the nearest $0.5 \mathrm{~cm}(18)$.

The standard physical activity questionnaire of PERSIAN cohort was implemented to assess participants' physical activity. The questionnaire consisted of 22 questions regarding the amount of an individual's daily activity. Finally, metabolic equivalent of task (MET), as an indicator for level and measure of physical activity, was extracted and entered into the model. MET is the amount of oxygen consumed at rest (about $3.5 \mathrm{ml} \mathrm{02} / \mathrm{kg} / \mathrm{min}$ ) and is equal to resting metabolic rate. MET for each activity was extracted using a compendium of physical activities(19). Diabetes was defined as having an FBG $126 \mathrm{mg} / \mathrm{dl}$ and/or being on diabetes medication and/or if the diabetes was confirmed by a health practitioner (20).self-report family history of hypertension including living and deceased were any biological blood relatives, ever told by a health professional that they have hypertension.

The outcome variable in this study Blood pressure were classified as latent variable with tow markers including SBP and DBP used quantitatively. Blood pressure was measured after 15 minutes of rest in sitting position. Both arms were measured twice with the cuff size adjusted to the arm circumference. Four BP measurements were taken to mean systolic and diastolic pressure (SBP and DBP) (21).

\section{Statistical Methods}

First, we conducted an exploratory factor analysis (EFA) to identify the latent variables underlying the observation variables. The principal component analysis (PCA) and varimax rotation was conducted to estimate the latent variables. The number of the extracted factors was chosen based on the factor eigenvalue (1). The economic welfare (wealth) variable was measured using 12 questions regarding housing, car, home appliances and other amenities by PCA method. Second, In order to create constructs (or factors), we applied confirmatory factor analysis (CFA) and we constructed an initial SEM. The objective of confirmatory factor analysis is to test whether the data fit a hypothesized measurement model. In the next step, SEM with maximum likelihood estimation (MLE) was applied to assess the conceptual model (Figure1). The SEM was used to study the direct and indirect relationships between a set of variables associated with hypertension. In the conceptual model, there are four latent variables including the main dependent variable, which is blood pressure, with the indicator of systolic and diastolic blood pressure (SBP, DBP). Considering that BMI, WHR and WC represent obesity indicators, a latent variable named 'obesity ' was constructed. The other latent variable that play the role of independent variable in the model include SES with three indicators: economic prosperity (Wealth); education level; and place of residence (place). The four latent variable named 'lipid profile' was constructed to reflect TC/HDL and LDL/HDL. Path standardized coefficients ( $\beta$ ) as the effect sizes of this model were calculated. CMIN/DF , CFI, GFI , RMSEA, NFI and AGFI were applied to assess fitness of the model. Also, data were described using the appropriate method (mean \pm standard deviation for 
quantitative variables and number and percentage (\%) for qualitative variable). All of the statistical analysis was performed using AMOS-SPSS 22 and STATA 14.0 (STATA Corp, College Station, TX). Pvalue less than 0.05 was considered as statistically significant.

\section{Results}

\section{Characteristics of study participants}

From among 10065 participants, 9705 subjects enrolled in this study. The mean age \pm SD of the participants was $47.53 \pm 8.47$ years. About $52 \%$ of the participants were female and $47 \%$ were male. The mean systolic blood pressure was $107.52 \pm 15.45$ and the mean diastolic blood pressure was $69.65 \pm 9.35$. The BMI of $>=30$ was $35 \%$ in women and $16 \%$ in men. The waist-to-hip ratio (WHR) >= 90 was 3257 (53\%) in women and 2908 (47\%) in men. The general characteristics of the study participants are shown in Table 1.

Table1: Demographic features in 35-65-year-old by sex at RaNCD chort study

The values outside the parentheses are the number of people and the values inside the parentheses are the percentages. Data are expressed as mean SD. P values were estimated using analysis variance or test.

\section{Results of latent analysis variables}

Exploratory factor analysis was conducted and the Kaiser-Meyer-Olk statistic was determined to be 0.697 , which indicated that the data were suitable for factor analysis. The four latent factors included SES, blood pressure, obesity, lipid profile were extracted with eigenvalue greater than 1 . The extraction results of the latent variables are shown in Table2. In the CFA between the latent variable in the model, correlation and fitting indexes were acceptable : chi-square value ()$=624.897$, the ratio of to the degrees of freedom $=25$, root mean square error of approximation $(\mathrm{RMSEA})=0.05$, comparative fit index $(\mathrm{CFI})=0.98$, goodness of fit index $(\mathrm{GFI})=0.987$, tuker- lewis index $(\mathrm{TLI})=0.981$. (Table3)

Table 2: Extraction results of latent analysis variables (Varimax rotation)

The result of exploratory factor analysis: Kaiser-meyer-olk in measure Of sampling adequacy $(\mathrm{kmo})=$ 0.697, Bartlett test of sphericity approx: Chi-square $=56799.689, \mathrm{p}$ SES socioeconomic status, SBP systolic blood pressure, DBP diastolic Blood pressure, WC waist circumference, BMI body mass index, WHR waist to hip ratio, LDL low-density lipoproteins, TC total cholesterol, HDL High-density lipoprotein.

Table 3 : standardized factor loading of the confirmatory factor analysis

SES socioeconomic status, SBP systolic blood pressure, DBP diastolic blood pressure, WC waist circumference, BMI body mass index, WHR waist to hip ratio, LDL low-density lipoproteins, TC total cholesterol, HDL High-density lipoprotein 


\section{Results of the model structure}

The conceptual model of the study included the variables extracted from the results of previous studies and a review of literature plus consultation with experts. The final model was constructed of the different models (Figure1) and was determined to be the most suitable and identified as the final model. In figure 2 and 3, variables of obesity, Diabetes, lipid profile and METs play a mediation effect which then lead to blood pressure. Table 4 shows the direct and indirect effects of risk factors associated with blood pressure for two groups. Obesity in women were associated with blood pressure directly $(B=0.15)$ and corresponding values in men were $(B=0.24)$. In men and women, the direct effect of SES on the blood pressure came out negative ( $B=-0.13$ vs $B=-0.17$ ), but it was positive indirect effect $(B=0.04$ vs $B=$ 0.03 ). The mediators for the indirect effect of SES on blood pressure were obesity, Diabetes and Mets (Figure 2, 3). Diabetes was directly associated with blood pressure in women $(B=0.03)$ but the association was not statistically significant in men. Mets were inversely indirect associated with blood pressure ( $B=-0.04$ vs $B=-0.04$ ), in men and women. The mediators for the indirect effect of Mets on blood pressure were obesity, Diabetes and lipid profile. Having positive family history of hypertension especially in the first-degree relatives were associated with a higher risk of hypertension in men and women. lipid profile were direct effect $(B=0.05$ vs $B=0.09)$ and indirect $\operatorname{effect}(B=0.08$ vs $B=0.04)$ in men and women. The mediators for the indirect effect of lipid profile on blood pressure were obesity, Diabetes. Taking antihypertensive drugs were inversely directly associated with blood pressure $(B=-0.29$ vs $\beta=-0.33$ ) in men and women. Table (4) shows the association between the variable.

Figure 2 and 3: shows structural equation models for assessing direct and indirect effects on blood pressure for both males and females by standardized path coefficient and goodness of fit indices. "e" represent the errors. Note. SBP systolic blood pressure; DBP diastolic blood pressure; WHR waist to hip ratio ; BMI body mass index; SES socioeconomic status, WC waist circumference, LDL low-density lipoproteins, TC total cholesterol, HDL High-density lipoprotein, HTNfamily Family history ohypertension, HTNdrug antihypertensive drugs,

Table 4. Direct and indirect effects derived from a SEM in people 35-65 from the RaNCD cohort study.

Note. SBP systolic blood pressure; DBP diastolic blood pressure; WHR waist to hip ratio; BMI body mass index; SES socioeconomic status, WC waist circumference, LDL low-density lipoproteins, TC total cholesterol, HDL High-density lipoprotein, HTNfamily Family history of hypertension, HTNdrug antihypertensive drug,

\section{Discussion}

hypertension is a major public health problem globally(22). Although many studies have examined the effect of risk factors for hypertension separately, only a few limited studies have evaluated the direct and indirect effects of risk and protective factors of hypertension by considering the role of the mediator variables. The present study was conducted to determine the direct and indirect effects of modifiable and non-modifiable risk factors of hypertension using SEM. Therefore, we constructed the latent variable path 
graph and the SEM model based on past theories. For a proper model fit, modifications had to be implemented on the conceptual model over the course of the statistical analysis based on adjustable indices suggested by the software. In our study, due to the high sample size Chi-square tests are not suitable for model fitting (23). although other fitting indices unrestricted by the sample size are good. Comparative fit index $(\mathrm{FCl})$, incremental fit index (IFI), and normed fit index (NFI) equal to or greater than 0.90 and Root Mean Square Error of Approximation (RMSEA) equal to less than 0.08 were applied to confirm the fit of the model.

With development of the medical research field, it has become important to study and analyze the relationship between social and behavioral factor that affect people's health. This study has demonstrated that individual with a higher level of SES had a direct negative and indirect positive effect through (obesity, MET, Diabetes) on hypertension and at increased risk for lipid profile and obesity in both sexes. Increased awareness, accessibility of medical treatment and opportunities to prevent, diagnosis of hypertension have been indicated a protective effect of higher SES on raised blood pressure. However, unfavorable living habits, unhealthy diet including the consumption of high-calorie foods (the average energy consumed by our whole population was $3865.56 \mathrm{kcal} / \mathrm{d}$, which was higher than the recommended levels) ,obesity and physical inactivity have been indicated an indirect positive effect of higher SES on raised blood pressure. This finding is consistent whit previous research that found that individual with a higher level of SES had a direct and indirect effect on hypertension with structural equation model(24, 25). Individuals with high level of SES should pay more attention to prevent the hypertension, since SES as a distal risk factor, indirectly influenced obesity, MET, Diabetes, Lipid profile through this pathway.

Obesity was the most important risk factor that directly affected the development of hypertension in our study in both sexes. Consistent with the results of SEM previous studies $(24,26)$.Overall, individuals who participated in the RaNCD $27.6 \%$ of all participants had a normal BMI, while the majority were overweight or obese, especially among women. For waist-to-hip ratio, there was a big difference between men and women. From a total of 9705 people (82.4\%) with an abnormal value, $60.4 \%$ and $39.6 \%$ Were women and men, respectively(17). Hypertension and obesity were associated with biological, behavioral, social and environmental risk factors(27). Obesity is a major risk factor for hypertension, and the association between hypertension and obesity has been confirmed in the past two decades. The combination of obesity and hypertension leads to an increased risk of developing cardiovascular complications(28).

In the present study, the lipid profile was directly associated with hypertension in both sexes, and was associated with obesity directly in Men and women. Many clinical studies have shown that the lipid profile is a strong marker for predicting the risk of atherosclerosis and heart diseases $(29,30)$. In most studies, old age, hypertension and obesity were significantly associated with an increased lipid profile and consequent dyslipidemia(31). The presence of hyperlipidemia is known to be a prognostic risk factor in patients with hypertension $(32,33)$.

The association between diabetes mellitus and serum lipids has been much debated over the past decades $(34,35)$. Type 2 diabetes mellitus (T2DM) is usually associated with abnormal levels of serum 
lipids. The interaction between impaired lipid metabolism and blood sugar plays an important role in the onset and progression of diabetes and related chronic complications $(36,37)$. In the present study, the lipid profile was directly associated with Diabetes in women. Higher level of Physical activity are associated with a decreased risk of $\operatorname{CVD}(38)$. We found that higher levels of physical activity were negative indirectly effect through decrease of mediator variables (obesity, lipid profile, Diabetes) on blood hypertension. in other words, physical activity was associated with a lower proportion of obesity, lipid profile, Diabetes consistent with previous SEM studies $(25,26)$.

\section{Strengths And Weaknesses}

This study has strengths and weaknesses. The most important strength of the present study was the sample size which was large enough to investigate the association between all the above mentioned variables with hypertension. Our study reveals advantages of SEM application for hypertension compared with the traditional analysis methods. In fact, SEM includes causal modeling, analysis of covariance structures, latent variable and robust model. SEM reduces measurement errors by involvement of several overt variables for each latent variable instead of single-measurement particularly with variables that are measured by multiple indicators, e.g.(SES, obesity, lipid profile) (39). However, our study is cross-sectional, which challenges the causal relationship between the variables. As well as the nature of hypertension which more than $90 \%$ of its causes are unknown, it was impossible to draw a model with a large number of variables due to the limitations of working with the software. Our study showed that although there are other factors associated with increased hypertension, among the modifiable risk factors obesity and antihypertensive drugs had the strongest direct effect on the outcome studied in this model. For future works we suggest conducting next studies on other incidence cases that may affect the development of hypertension, such as the role of various diseases, dietary patterns, drug use, the role of psychological and behavioral factors, and so on.

\section{Conclusion}

the present study demonstrated that high blood pressure was related to SES, physical activity, lipid profile, obesity and Diabetes directly and (or) in directly. Future interventions to prevent and control hypertension among Ravansar province should focus on SES, obesity, increasing physical activity and improving the life style.

\section{Declarations}

Ethics approval and consent to participate: the present study was conducted according to the Helsinki Declaration. The study was approved by the ethics committee of the vice chancellery of research and technology, Kermanshah University of Medical Sciences(IR.KUMS.REC.1394.315) and the written informed consent was obtained from each participant after explaining the purpose of research.

Consent for publication: Not applicable 
Availability of data and materials: The RaNCD cohort is not an open-access database. However, we would encourage external investigators to consider applying to use the data for secondary analyses, to maximize the scientific output from the data. All the information on how to access the RaNCD public data archive, with a list of current proposals and papers under preparation, can be found on our website: www.persiancohort.com

Competing interests: The authors declare that they have no competing interests.

Funding: This study was supported by Ministry of Health and Medical Education of Iran and Kermanshah University of Medical Science (Grant No: 92472) supported this study.

Authors' contributions: Farid Najafi interpretation of data and analysis and revised..Mehdi Moradinazar design of work, Shahab Rezayan contributions to the conception and revised, Reza Azarpazhooh contributions to the conception and revised. Parastoo jamshidi interpretation of data and writing and analysis.

Acknowledgments : RaNCD is part of PERSIAN national cohort and we would like to thank Professor Reza Malekzadeh Deputy of Research and Technology at the Ministry of Health and Medical Education of Iran and Director of the PERSIAN cohort and also Dr.Hossein Poustchi Executive Director of PERSIAN cohort for all their supports during design and running of RaNCD.

\section{References}

1. Sudhakar C, Rahman R. Study of blood pressure profile and anthropometry in children belonging to low socio-economic status; a prospective cross sectional study. International Journal of Contemporary Pediatrics. 2017;4(4):1179-84.

2. Azizi F, Ghanbarian A, Madjid M, Rahmani M. Distribution of blood pressure and prevalence of hypertension in Tehran adult population: Tehran Lipid and Glucose Study (TLGS), 1999-2000. Journal of human hypertension. 2002;16(5):305.

3. Tran J, Mirzaei M, Leeder S, editors. Hypertension: its prevalence and population-attributable fraction for mortality from stroke in the Middle East and north Africa. Circulation; 2010: LIPPINCOTT WILLIAMS \& WILKINS 530 WALNUT ST, PHILADELPHIA, PA 19106-3621 USA.

4. Kearney PM, Whelton M, Reynolds K, Muntner P, Whelton PK, He J. Global burden of hypertension: analysis of worldwide data. The lancet. 2005;365(9455):217-23.

5. Britton KA, Gaziano JM, Djoussé L. Normal systolic blood pressure and risk of heart failure in US male physicians. European journal of heart failure. 2009;11(12):1129-34.

6. Kalaitzidis RG, Bakris GL. Prehypertension: is it relevant for nephrologists? Kidney international. 2010;77(3):194-200.

7. Brown DW, Giles WH, Greenlund KJ. Blood pressure parameters and risk of fatal stroke, NHANES II mortality study. American journal of hypertension. 2007;20(3):338-41. 
8. Johnson RJ, Segal MS, Sautin Y, Nakagawa T, Feig DI, Kang D-H, et al. Potential role of sugar (fructose) in the epidemic of hypertension, obesity and the metabolic syndrome, diabetes, kidney disease, and cardiovascular disease- . The American journal of clinical nutrition. 2007;86(4):899906.

9. Laaksonen DE, Niskanen L, Nyyssönen K, Lakka TA, Laukkanen JA, Salonen JT. Dyslipidaemia as a predictor of hypertension in middle-aged men. European Heart Journal. 2008;29(20):2561-8.

10. Bruce MA, Beech BM, Norris KC, Griffith DM, Sims M, Thorpe Jr RJ. Sex, Obesity, and Blood Pressure Among African American Adolescents: The Jackson Heart KIDS Pilot Study. American journal of hypertension. 2017;30(9):892-8.

11. Garber A, Handelsman Y, Einhorn D, Bergman D, Bloomgarden Z, Fonseca V, et al. Diagnosis and management of prediabetes in the continuum of hyperglycemia-when do the risks of diabetes begin? A consensus statement from the American College of Endocrinology and the American Association of Clinical Endocrinologists. Endocrine practice. 2008;14(7):933-46.

12. Micklesfield LK, Munthali RJ, Prioreschi A, Said-Mohamed R, Van Heerden A, Tollman S, et al. Understanding the relationship between socio-economic status, physical activity and sedentary behaviour, and adiposity in young adult South African women using structural equation modelling. International journal of environmental research and public health. 2017;14(10):1271.

13. Bollen K. (1989b). Structural equations with latent variables. New York: John Wiley. 1989.

14. Hooman HA. Structural equation modeling with LISREL application. Tehran, SAMT Publications. 2005.

15. Hoyle RH. Handbook of structural equation modeling: Guilford press; 2012.

16. Poustchi H, Eghtesad S, Kamangar F, Etemadi A, Keshtkar A-A, Hekmatdoost A, et al. Prospective epidemiological research studies in Iran (the PERSIAN Cohort Study): rationale, objectives, and design. American journal of epidemiology. 2018;187(4):647-55.

17. Pasdar Y, Najafi F, Moradinazar M, Shakiba E, Karim H, Hamzeh B, et al. Cohort profile: Ravansar Non-Communicable Disease cohort study: the first cohort study in a Kurdish population. International journal of epidemiology. 2019;48(3):682-3f.

18. Organization WH. Waist circumference and waist-hip ratio: report of a WHO expert consultation, Geneva, 8-11 December 2008. 2011.

19. Karyani AK, Matin BK, Soltani S, Rezaei S, Soofi M, Salimi Y, et al. Socioeconomic gradient in physical activity: findings from the PERSIAN cohort study. BMC public health. 2019;19(1):1312.

20. Moradinazar M, Pasdar Y, Najafi F, Shakiba E, Hamzeh B, Samadi M, et al. Validity of self-reported diabetes varies with sociodemographic charecteristics: Example from Iran. Clinical Epidemiology and Global Health. 2020;8(1):70-5.

21. Najafı F, Pasdar Y, Shakiba E, Hamzeh B, Darbandi M, Moradinazar M, et al. Validity of Self-reported Hypertension and Factors Related to Discordance Between Self-reported and Objectively Measured Hypertension: Evidence From a Cohort Study in Iran. Journal of Preventive Medicine and Public Health. 2019;52(2):131. 
22. Cheng S, Claggett B, Correia AW, Shah AM, Gupta DK, Skali H, et al. Temporal trends in the population attributable risk for cardiovascular disease: the Atherosclerosis Risk in Communities Study. Circulation. 2014;130(10):820-8.

23. Preacher KJ, Hayes AF. Asymptotic and resampling strategies for assessing and comparing indirect effects in multiple mediator models. Behavior research methods. 2008;40(3):879-91.

24. Xiao L, Le C, Wang G-Y, Fan L-M, Cui W-L, Liu Y-N, et al. Socioeconomic and lifestyle determinants of the prevalence of hypertension among elderly individuals in rural southwest China: a structural equation modelling approach. BMC cardiovascular disorders. 2021;21(1):1-10.

25. Ma Z, Li D, Zhan S, Sun F, Xu C, Wang Y, et al. Analysis of risk factors of metabolic syndrome using a structural equation model: a cohort study. Endocrine. 2019;63(1):52-61.

26. Bardenheier BH, Bullard KM, Caspersen CJ, Cheng YJ, Gregg EW, Geiss LS. A novel use of structural equation models to examine factors associated with prediabetes among adults aged 50 years and older: National Health and Nutrition Examination Survey 2001-2006. Diabetes care. 2013;36(9):2655-62.

27. van der Sande MA, Walraven GE, Milligan PJ, Banya WA, Ceesay SM, Nyan OA, et al. Family history: an opportunity for early interventions and improved control of hypertension, obesity and diabetes. Bulletin of the World health organization. 2001;79:321-8.

28. FOR EPOIG, CHILDREN RRI. Expert panel on integrated guidelines for cardiovascular health and risk reduction in children and adolescents: summary report. Pediatrics. 2011;128(Suppl 5):S213.

29. Nwagha U, Ikekpeazu E, Ejezie F, Neboh E, Maduka I. Atherogenic index of plasma as useful predictor of cardiovascular risk among postmenopausal women in Enugu, Nigeria. African health sciences. 2010;10(3).

30. Rajab TMA. Comparative study for atherogenic index of plasma AIP in patient with type1 diabetes mellitus, type2diabetes mellitus, Betathalassemia and hypothyroidism. Inter J Chem Res. 2012;2(2):1-9.

31. Hamam F. Dyslipidemia and related risk factors in a Saudi university community. Food and Nutrition Sciences. 2017;8(01):56.

32. Yousefi R, Mobarhan MG, Esmaily H, Saki A, Ferns GA, Tayefı M. Identifying factors associated with hypertension using structural equation modeling: a population-based study. Iranian Rehabilitation Journal. 2018;16(3):307-16.

33. Roman-Urrestarazu A, Ali FMH, Reka H, Renwick MJ, Roman GD, Mossialos E. Structural equation model for estimating risk factors in type 2 diabetes mellitus in a Middle Eastern setting: evidence from the STEPS Qatar. BMJ Open Diabetes Research and Care. 2016;4(1):e000231.

34. Elnasri $\mathrm{H}$, Ahmed A. Patterns of lipid changes among type 2 diabetes patients in Sudan. EMHJEastern Mediterranean Health Journal, 14 (2), 314-324, 2008. 2008.

35. Dixit AK, Dey R, Suresh A, Chaudhuri S, Panda AK, Mitra A, et al. The prevalence of dyslipidemia in patients with diabetes mellitus of ayurveda Hospital. Journal of Diabetes \& Metabolic Disorders. 2014;13(1):58. 
36. Khan H, Sobki S, Khan S. Association between glycaemic control and serum lipids profile in type 2 diabetic patients: HbA 1c predicts dyslipidaemia. Clinical and experimental medicine. 2007;7(1):249.

37. Dixit AK, Dey R, Suresh A, Chaudhuri S, Panda AK, Mitra A, et al. The prevalence of dyslipidemia in patients with diabetes mellitus of ayurveda Hospital. Journal of Diabetes \& Metabolic Disorders. 2014;13(1):1-6.

38. Kanthe PS, Patil BS, Bagali S, Shaikh GB, Aithala M. Atherogenic index as a predictor of cardiovascular risk among women with different grades of obesity. International Journal of Collaborative Research on Internal Medicine \& Public Health. 2012;4(10):0-.

39. Shi F, Gao W, Tao E, Liu H, Wang S. Metabolic syndrome is a risk factor for nonalcoholic fatty liver disease: evidence from a confirmatory factor analysis and structural equation modeling. Eur Rev Med Pharmacol Sci. 2016;20(20):4313-21.

\section{Tables}

Table 1 is available in the Supplemental Files section.

Table 2: Extraction results of latent analysis variables (Varimax rotation) 


\begin{tabular}{|c|c|c|c|}
\hline $\begin{array}{l}\text { Latent } \\
\text { variable }\end{array}$ & $\begin{array}{l}\text { Indicator } \\
\text { variable }\end{array}$ & $\begin{array}{l}\text { Loading } \\
\text { coefficient }\end{array}$ & $\begin{array}{l}\text { Cronbach's } \\
\text { coefficient }\end{array}$ \\
\hline \multirow[t]{4}{*}{ Blood pressure } & SBP & 0.953 & 0.863 \\
\hline & DBP & 0.958 & \\
\hline & & & 0.589 \\
\hline & Education & 0.832 & \\
\hline \multirow[t]{2}{*}{ SES } & Wealth & 0.802 & \\
\hline & Place & 0.585 & 0.962 \\
\hline \multirow[t]{3}{*}{ Lipid profile } & LDL: HDL & 0.973 & 0.549 \\
\hline & TC: HDL & 0.972 & \\
\hline & $\mathrm{BMI}$ & & \\
\hline \multirow[t]{3}{*}{ Obesity } & WC & 0.916 & \\
\hline & WHR & 0.905 & \\
\hline & & 0.836 & \\
\hline
\end{tabular}

The result of exploratory factor analysis: Kaiser-meyer-olk in measure Of sampling adequacy $(\mathrm{kmo})=$ 0.697 , Bartlett test of sphericity approx: Chi-square $=56799.689, p<0.001$

SES socioeconomic status, SBP systolic blood pressure, DBP diastolic Blood pressure, WC waist circumference, BMI body mass index, WHR waist to hip ratio, LDL low-density lipoproteins, TC total cholesterol, HDL High-density lipoprotein

Table 3 : standardized factor loading of the confirmatory factor analysis 


\begin{tabular}{|c|c|c|}
\hline Latent variables & Indicator variables & Loading cofficint \\
\hline \multirow[t]{2}{*}{ Blood pressure } & SBP & 0.958 \\
\hline & DBP & 0.950 \\
\hline \multirow[t]{3}{*}{ SES } & Education & 0.644 \\
\hline & Wealth & 0.801 \\
\hline & Place & 0.335 \\
\hline \multirow[t]{3}{*}{ Lipid profile } & LDL: HDL & 0.959 \\
\hline & TC: HDL & 0.980 \\
\hline & $\mathrm{BMI}$ & 0.741 \\
\hline \multirow[t]{2}{*}{ Obesity } & WC & 0.696 \\
\hline & WHR & 0.925 \\
\hline
\end{tabular}

SES socioeconomic status, SBP systolic blood pressure, DBP diastolic blood pressure, WC waist circumference, BMI body mass index, WHR waist to hip ratio, LDL low-density lipoproteins, TC total cholesterol,HDL High-density lipoprotein

Table 4: Direct and indirect effects derived from a SEM in people 35-65 from the RaNCD cohort study. 


\begin{tabular}{|c|c|c|c|c|c|c|}
\hline \multirow[t]{3}{*}{ Variables } & \multicolumn{3}{|l|}{ Male } & \multicolumn{3}{|l|}{ Female } \\
\hline & & \multirow{2}{*}{$\begin{array}{l}\text { Direct } \\
\text { effect } \\
\mathbf{( 9 5 \% \mathrm { Cl } )}\end{array}$} & \multirow{2}{*}{$\begin{array}{l}\text { Indirect } \\
\text { effect } \\
(95 \% \mathrm{Cl})\end{array}$} & \multirow{2}{*}{$\begin{array}{l}\text { Total } \\
\text { effect } \\
(95 \% \mathrm{Cl})\end{array}$} & \multirow{2}{*}{$\begin{array}{l}\text { Direct } \\
\text { effect } \\
\mathbf{( 9 5 \% \mathrm { Cl } )}\end{array}$} & \multirow{2}{*}{$\begin{array}{l}\text { Indirect } \\
\text { effect } \\
(95 \% \mathrm{Cl})\end{array}$} \\
\hline & $(95 \% \mathrm{Cl})$ & & & & & \\
\hline $\begin{array}{l}\text { Obesity }-> \\
\text { BP }\end{array}$ & $\begin{array}{l}0.24(0.21- \\
0.27)\end{array}$ & $\begin{array}{l}0.24(0.21- \\
0.27)\end{array}$ & - & $\begin{array}{l}0.15(0.12- \\
0.18)\end{array}$ & $\begin{array}{l}0.15(0.12- \\
0.18)\end{array}$ & - \\
\hline $\operatorname{Lipid~profile-~}_{\rightarrow B P}$ & $\begin{array}{l}0.13(0.10- \\
0.16)\end{array}$ & $\begin{array}{l}0.05(0.02- \\
0.08)\end{array}$ & $\begin{array}{l}0.08(0.06 \text { - } \\
0.09)\end{array}$ & $\begin{array}{l}0.13(0.10 \\
0.15)\end{array}$ & $\begin{array}{l}0.09(0.07 \\
0.12)\end{array}$ & $\begin{array}{l}0.04(0.02, \\
0.05)\end{array}$ \\
\hline $\mathrm{SES} \rightarrow \mathrm{BP}$ & $\begin{array}{l}-0.09(-0.13 \\
-0.06)\end{array}$ & $\begin{array}{l}-0.13(-0.17, \\
-0.09)\end{array}$ & $\begin{array}{l}0.04(0.02, \\
0.05)\end{array}$ & $\begin{array}{l}-0.14(-0.18 \\
-0.06)\end{array}$ & $\begin{array}{l}-0.17(-0.20 \\
-0.13)\end{array}$ & $\begin{array}{l}0.03(0.02, \\
0.04)\end{array}$ \\
\hline $\begin{array}{l}\text { Diabetes--> } \\
\text { BP }\end{array}$ & - & - & - & $\begin{array}{l}0.03(0.02 \\
0.05)\end{array}$ & $\begin{array}{l}0.03(0.02, \\
0.05)\end{array}$ & - \\
\hline MET $\rightarrow$ BP & $\begin{array}{l}-0.04(-0.07 \\
-0.01)\end{array}$ & - & $\begin{array}{l}-0.04(-0.07 \\
-0.01)\end{array}$ & $\begin{array}{l}-0.04(-0.07 \\
-0.02)\end{array}$ & - & $\begin{array}{l}-0.04(-0.07, \\
-0.02)\end{array}$ \\
\hline $\begin{array}{l}\text { HTNDRUG -- } \\
>\text { BP }\end{array}$ & $\begin{array}{l}-0.29 \\
(-0.32 \\
-0.25)\end{array}$ & $\begin{array}{l}-0.29 \\
(-0.32 \\
-0.25)\end{array}$ & - & $\begin{array}{l}-0.33 \\
(-0.36 \\
-0.30)\end{array}$ & $\begin{array}{l}-0.33 \\
(-0.36 \\
-0.30)\end{array}$ & - \\
\hline $\begin{array}{l}\text { HTN family-- } \\
>\text { BP }\end{array}$ & $\begin{array}{l}0.02(0.02 \\
0.05)\end{array}$ & $\begin{array}{l}0.02(0.02, \\
0.05)\end{array}$ & - & $\begin{array}{l}0.03(0.01 \\
0.06)\end{array}$ & $\begin{array}{l}0.03(0.01 \\
0.06)\end{array}$ & - \\
\hline $\begin{array}{l}\text { MET - } \\
\text { obesity }\end{array}$ & $\begin{array}{l}-0.11 \\
(-0.15 \\
-0.08)\end{array}$ & $\begin{array}{l}-0.08 \\
(-0.11 \\
-0.05)\end{array}$ & $\begin{array}{l}-0.03(-0.04, \\
-0.02)\end{array}$ & $\begin{array}{l}-0.08 \\
(-0.11 \\
-0.05)\end{array}$ & $\begin{array}{l}-0.07 \\
(-0.10 \\
-0.04)\end{array}$ & $\begin{array}{l}-0.01 \\
(-0.01 \\
-0.03)\end{array}$ \\
\hline $\begin{array}{l}\text { MET--> lipid } \\
\text { profile }\end{array}$ & $\begin{array}{l}-0.11 \\
(-0.13 \\
-0.07)\end{array}$ & $\begin{array}{l}-0.11 \\
(-0.13 \\
-0.07)\end{array}$ & - & $\begin{array}{l}-0.07 \\
(-0.09 \\
-0.04)\end{array}$ & $\begin{array}{l}-0.07 \\
(-0.09 \\
-0.04)\end{array}$ & - \\
\hline $\begin{array}{l}\text { MET--> } \\
\text { Diabetes }\end{array}$ & $\begin{array}{l}-0.06 \\
(-0.09 \\
-0.03)\end{array}$ & $\begin{array}{l}-0.06(-0.09 \\
-0.03)\end{array}$ & - & $\begin{array}{l}-0.03(-0.09 \\
-0.03)\end{array}$ & $\begin{array}{l}-0.02 \\
(-0.05 \\
-0.03)\end{array}$ & $\begin{array}{l}-0.01 \\
(-0.01 \\
-0.03)\end{array}$ \\
\hline $\begin{array}{l}\text { Lipidprofile- } \\
\text { >obesity }\end{array}$ & $\begin{array}{l}0.32(0.30 \\
0.35)\end{array}$ & $\begin{array}{l}0.32(0.30 \\
0.35)\end{array}$ & - & $\begin{array}{l}0.21(0.18 \\
0.24)\end{array}$ & $\begin{array}{l}0.21(0.18 \\
0.24)\end{array}$ & - \\
\hline SES- $\rightarrow$ METs & $\begin{array}{l}-0.39 \\
(-0.41 \\
-0.36)\end{array}$ & $\begin{array}{l}-0.39 \\
(-0.41 \\
-0.36)\end{array}$ & - & $\begin{array}{l}-0.23 \\
(-0.26 \\
-0.19)\end{array}$ & $\begin{array}{l}-0.23 \\
(-0.26 \\
-0.19)\end{array}$ & - \\
\hline $\begin{array}{l}\text { SES->> } \\
\text { Obesity }\end{array}$ & $\begin{array}{l}0.13(0.09, \\
0.16)\end{array}$ & $\begin{array}{l}0.08(0.04, \\
0.12)\end{array}$ & $\begin{array}{l}0.05(0.03 \\
0.06)\end{array}$ & $\begin{array}{l}0.10(0.06, \\
0.13)\end{array}$ & $\begin{array}{l}0.08(0.04 \\
0.12)\end{array}$ & $\begin{array}{l}0.02(0.01, \\
0.02)\end{array}$ \\
\hline $\begin{array}{l}\text { SES->> Lipid } \\
\text { profile }\end{array}$ & $\begin{array}{l}0.04(0.03, \\
0.05)\end{array}$ & - & $\begin{array}{l}0.04(0.03 \\
0.05)\end{array}$ & $\begin{array}{l}0.01(0.01 \\
0.02)\end{array}$ & - & $\begin{array}{l}0.01(0.01, \\
0.02)\end{array}$ \\
\hline $\begin{array}{l}\text { Lipid profile - } \\
\rightarrow \text { Diabetes }\end{array}$ & - & - & - & $\begin{array}{l}0.04 \\
(0.01,0.07)\end{array}$ & $\begin{array}{l}0.04 \\
(0.01,0.07)\end{array}$ & - \\
\hline
\end{tabular}


SBP systolic blood pressure, DBP diastolic blood pressure, SES socioeconomic status, HTN family:Family history of hypertension, HTNdrug antihypertensive drugs

\section{Figures}

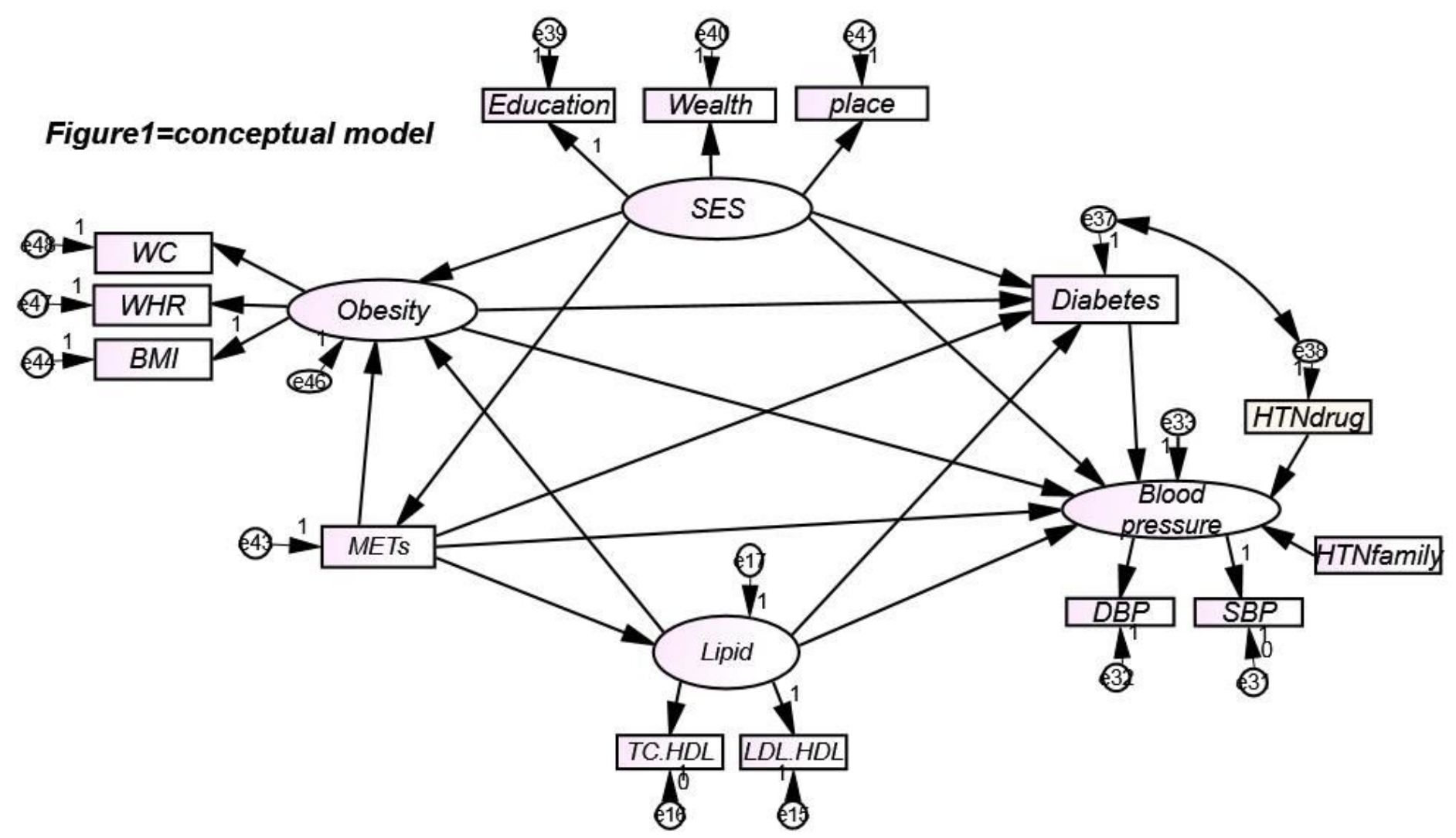

\section{Figure 1}

The conceptual model diagram for risk factors relationship with blood pressure.

SES socioeconomic status, SBP systolic blood pressure, DBP diastolic Blood pressure, WC waist circumference, BMI body mass index, WHR waist to hip ratio, LDL low-density lipoproteins, TC total cholesterol, HDL High-density lipoprotein, HTNfamily Family history of hypertension, HTNdrug antihypertensive drugs 


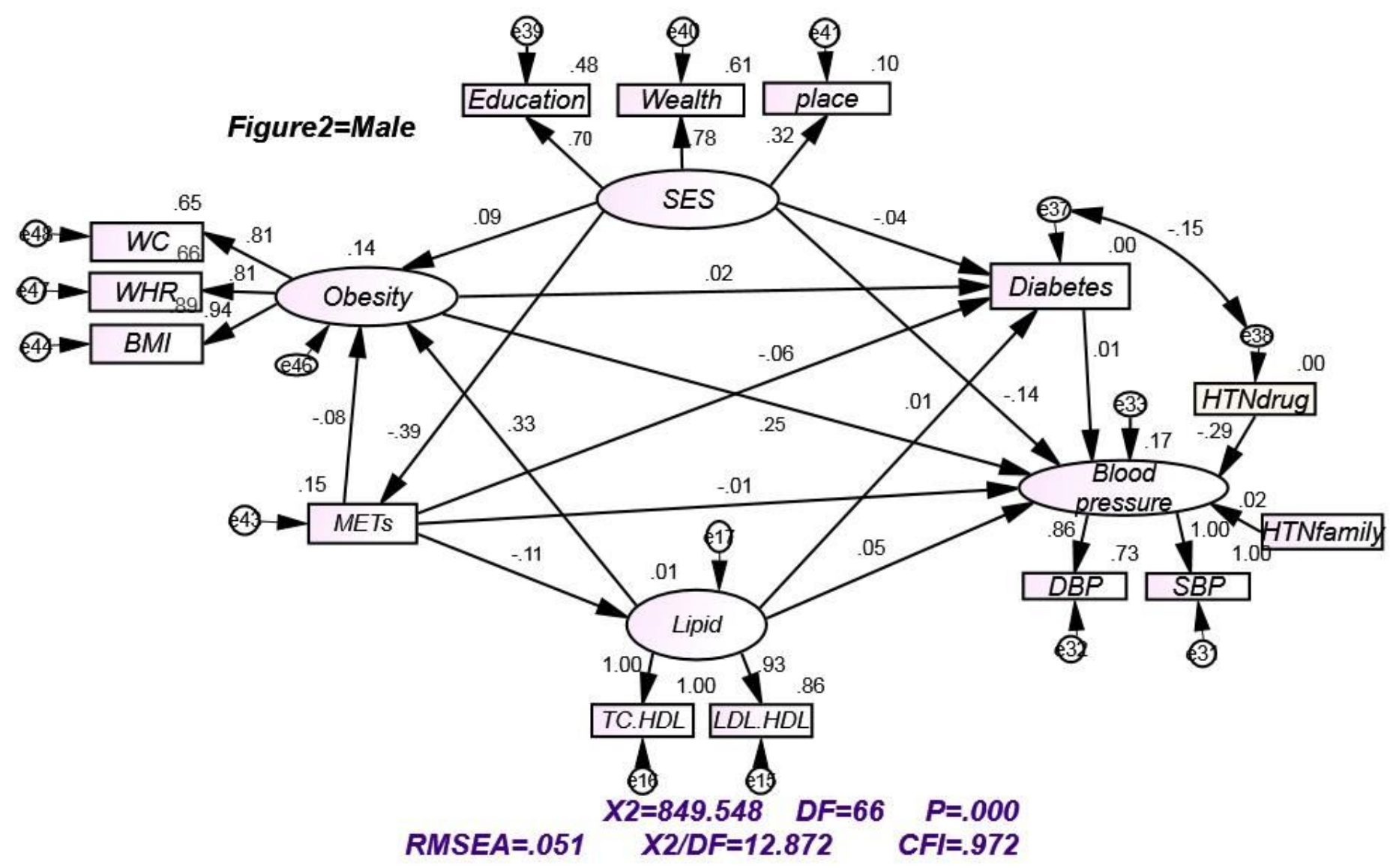

Figure 2

Figure 2: shows structural equation models for assessing direct and indirect effects on blood pressure for both males and females by standardized path coefficient and goodness of fit indices. "e" represent the errors. Note. SBP systolic blood pressure; DBP diastolic blood pressure; WHR waist to hip ratio ; BMI body mass index; SES socioeconomic status, WC waist circumference, LDL low-density lipoproteins, TC total cholesterol, HDL High-density lipoprotein, HTNfamily Family history ohypertension, HTNdrug antihypertensive drugs, 


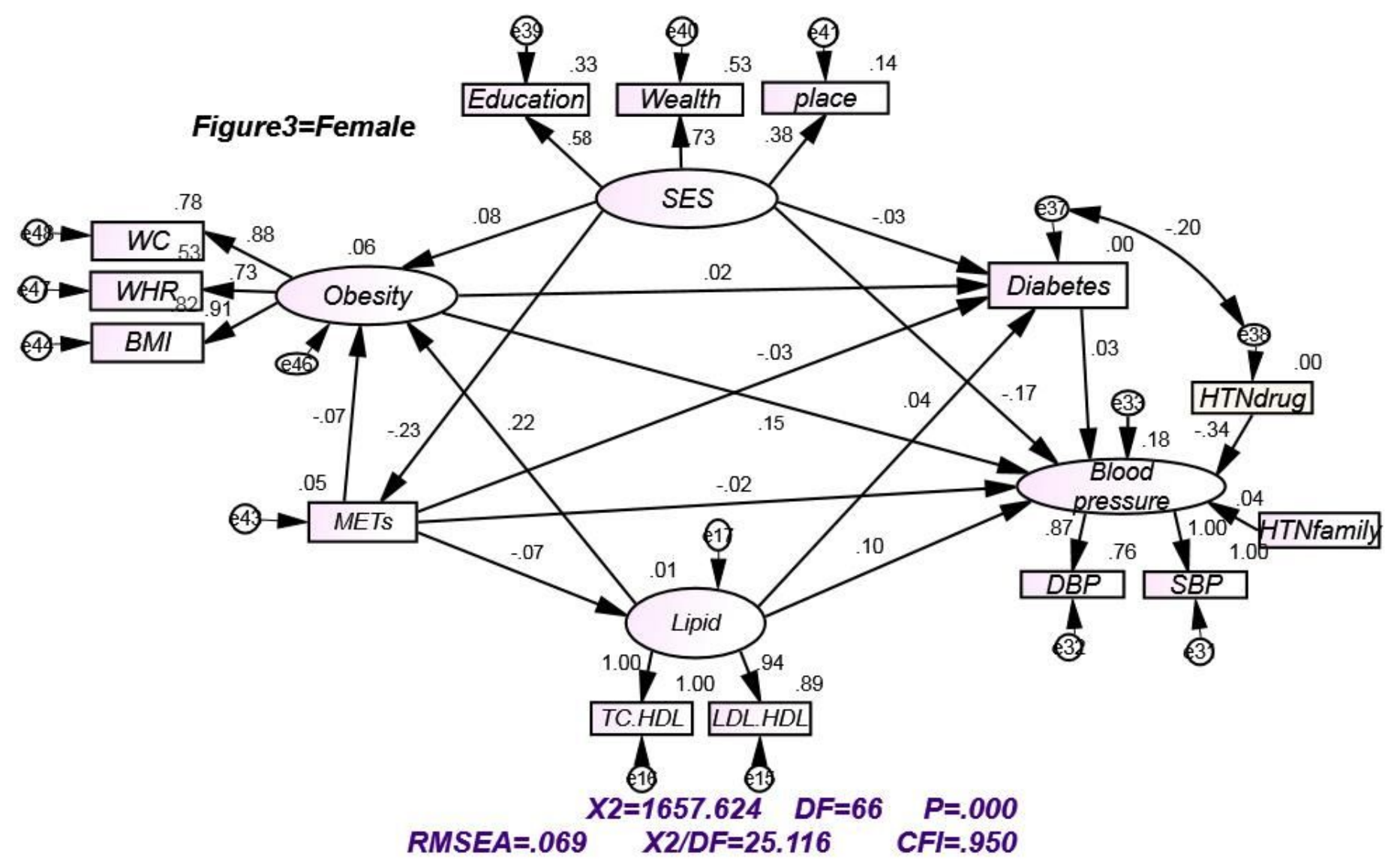

Figure 3

Figure 3: shows structural equation models for assessing direct and indirect effects on blood pressure for both males and females by standardized path coefficient and goodness of fit indices. "e" represent the errors. Note. SBP systolic blood pressure; DBP diastolic blood pressure; WHR waist to hip ratio ; BMI body mass index; SES socioeconomic status, WC waist circumference, LDL low-density lipoproteins, TC total cholesterol, HDL High-density lipoprotein, HTNfamily Family history ohypertension, HTNdrug antihypertensive drugs,

\section{Supplementary Files}

This is a list of supplementary files associated with this preprint. Click to download.

- Table1.jpg 